\title{
Fatal Superior Vena Cava Syndrome after Endoscopic Variceal Sclerotherapy
}

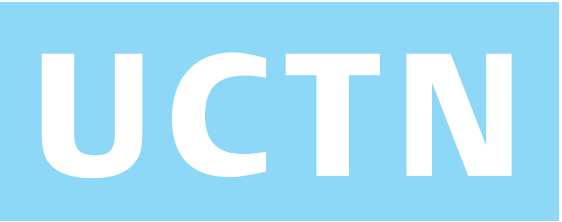

A 50-year-old woman with primary biliary cirrhosis (Child-Pugh class C) was admitted with esophageal variceal bleeding, and emergency endoscopic variceal sclerotherapy (EVS) with $16 \mathrm{ml}$ of $5 \%$ ethanolamine oleate was carried out. She had experienced two episodes of variceal bleeding during the previous 6 months and had been treated with emergency EVS, followed by weekly elective sessions, receiving a total of $90 \mathrm{ml}$ of ethanolamine oleate. Four days after the last EVS session, the patient developed marked edema in the right arm. Chest computed tomography and cardiac ultrasonography were normal. Contrast venography revealed partial obstructions of the right brachiocephalic and right subclavian veins (Figure 1). She progressively developed neck and face edema, jugular congestion, and dilated veins in the head and anterior chest wall, indicating the development of superior vena cava syndrome. There was no evidence of infection, and a central venous catheter had not been placed. The portal venous system was patent on Doppler ultrasonography. Acquired and inherited thrombophilic factors were excluded. Steroids failed to bring about clinical improvement, and the patient died a few days later.

EVS is a first-line treatment for bleeding esophageal varices [1]. Although local complications of EVS are frequent, widespread complications are rarely seen [2]. A causal relationship between EVS and portal vein thrombosis has been suggested [3]. However, to the best of our knowledge, an association with superior vena cava syndrome has not previously been reported. There is ample evidence to suggest that most of the flow of the intravariceally injected sclerosant is toward the azygous system, through the esophageal and paraesophageal veins $[4,5]$. It may be speculated that the dissemination of the sclerosant resulted in venous wall changes [3], leading to extensive local thrombosis, and subsequently to superior vena cava syndrome. Potential thrombosis of the major thoracic veins therefore be

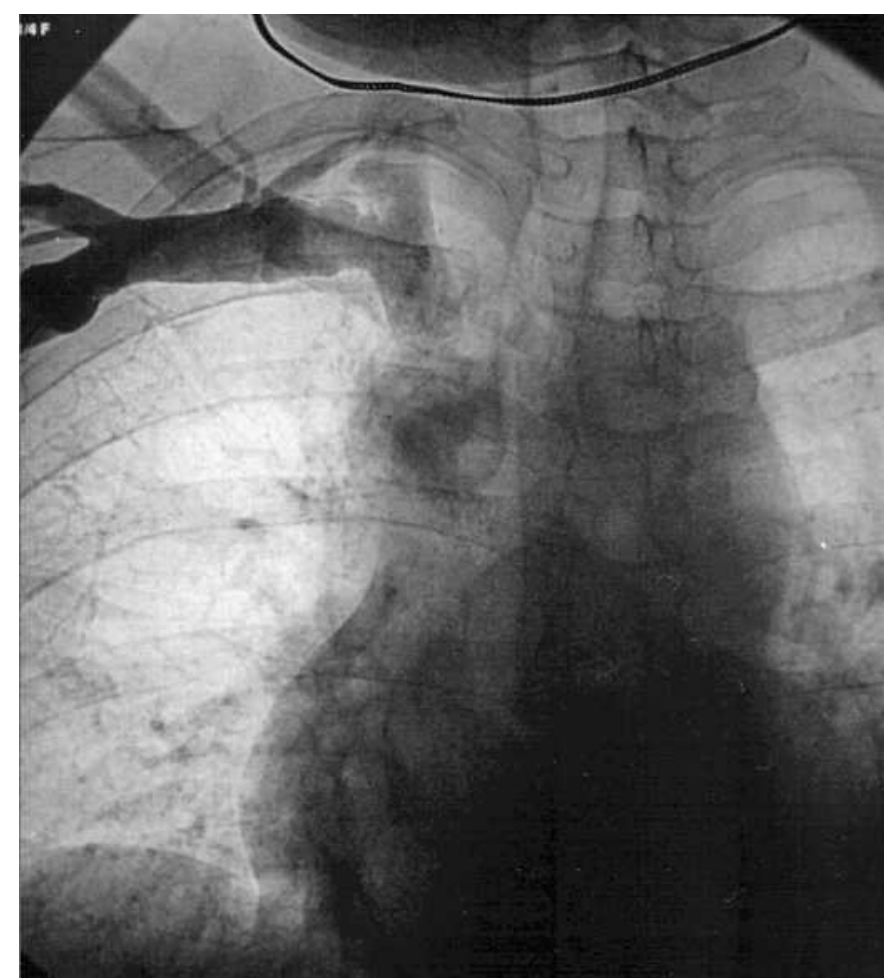

Figure 1 Right brachial venography, showing a major partial obstruction of the right brachiocephalic vein at its junction with the left brachiocephalic vein and a minor partial obstruction of the right subclavian vein at its junction with the right internal jugular vein, causing retrograde opacification of the latter vein.

borne in mind in patients treated with EVS.

\section{G. Kalambokis ${ }^{1}$, P. Nikolopoulos ${ }^{2}$, N. Tzambouras ${ }^{3}$, M. Economou ${ }^{3}$, E. V. Tsianos ${ }^{1,3}$ \\ ${ }^{1}$ Dept. of Internal Medicine, Medical School of Ioannina, Ioannina, Greece \\ 2 Dept. of Radiology, Medical School of Ioannina, Ioannina, Greece \\ ${ }^{3}$ Dept. of Gastroenterology, Medical School of Ioannina, Ioannina, Greece.}

\section{References}

${ }^{1}$ Westaby D, Hayes PC, Gimson AE et al. Controlled clinical trial of injection sclerotherapy for active variceal bleeding. Hepatology 1989; 9: 274-277

${ }^{2}$ Heaton ND, Howard ER. Complications and limitations of injection sclerotherapy in portal hypertension. Gut 1993; 34: 7-10

${ }^{3}$ Hunter GC, Steinkirchner T, Burbige EJet al. Venous complications of sclerotherapy for esophageal varices. Am J Surg 1988; 156: 497-501

${ }^{4}$ Barsoum MS, Khattar NY, Risk-Allah MA. Technical aspects of injection sclerotherapy of acute oesophageal variceal hemorrhage as seen by radiography. Br J Surg 1978; 65: $588-589$

${ }^{5}$ Soderlund C, Backman L, Erwald R. Sclerotherapy of esophageal varices: an endoscopic and portographic study. Hepatology 1984; 4: 877-884

\section{Corresponding Author}

\section{E. V. Tsianos, M.D.}

Medical School of Ioannina Panepistimiou

45110 Ioannina

Greece

Fax: $\quad+30-2651097016$

E-mail: geodora@mail.gr 